\title{
Machines among the crowd: on the political effects of algorithmic production of social currents'
}

\author{
Jair de Souza Ramos' \\ 'Faculdade de Sociologia, Programa de Pós-Graduação em Sociologia, \\ Universidade Federal Fluminense, Niterói/RJ, Brasil
}

\begin{abstract}
In this paper, I discuss a few ways that mechanisms for collective action are reconfigured by the activity of digital communication technologies. In particular, I examine how algorithms mobilized on the Social Web co-participate in the regulation of interdependence between the elements that compose contemporary figurations through the following mechanisms: by the production and organization of sociality by curating content, recommendations, and instructions for users; by their impact on the social production of the categories of time, space and identity; by the expansion of a business model that interlaces algorithmic activity and human action; and by the reconfiguration of the social modes of production and dissemination of knowledge. I conclude with the examination of the political consequences of this algorithmic activity in the production of social currents.
\end{abstract}

Key words: Political mobilization; Cyberactivism; Algorithms.

\footnotetext{
1 This article originated from my participation in the panel discussion "Freedom, Emancipation, Democracy: The paradoxes of the digital" in November 2018 at the Maison de France Library in Rio de Janeiro, to which I was invited by professor Jorge de La Barre (UFF), alongside professors Dejan Dimitrijevic (Lyon II) and Laura Graziela Gomes (UFF). Produced in an interaction with Laura Gomes, this article was designed to offer a broad and therefore more theoretical approach to the tensions between digital and political institutions, while Laura's article analyzed the same subject by taking a specific empirical situation as a starting point.
} 


\section{No meio da multidão, as máquinas: sobre os efeitos políticos da produção algorítmica de correntes sociais}

\section{Resumo}

Neste artigo, discuto algumas maneiras pelas quais os mecanismos de ação coletiva são reconfigurados pela atividade de tecnologias digitais de comunicação. Em especial, examino o modo como os algoritmos mobilizados na Web Social coparticipam da regulação da interdependência entre os elementos que compõem as figurações contemporâneas através dos seguintes mecanismos: pela produção e organização de socialidades através da curadoria dos conteúdos e das recomendações e prescrições dirigidas aos usuários. Pelo seu impacto na produção social das categorias de tempo, espaço e identidade. Pela expansão de um modelo de negócios que entrelaça atividade algorítmica e ação humana. Pela reconfiguração dos modos sociais de produção e difusão de conhecimento. Concluo com o exame das consequências políticas dessa atividade algorítmica na produção de correntes sociais.

Palavras-chave: Mobilização política; Ciberativismo; Algoritmos. 


\title{
Machines among the crowd: on the political effects of algorithmic production of social currents
}

\author{
Jair de Souza Ramos
}

\section{Construction of the problem}

Digital communication technologies, which constitute and are constituted by the Internet, have played an increasingly important role in social practices that have long been examined by sociology. One of these areas of research is politics, and my goal in this article is to analyze some of the changes that the internet has brought to this field. To do so, I present a question that based on the articulation of three ideas.

Two of these ideas are inspired by the work of sociologist Norbert Elias. Firstly, he argues that what we call society consists of figurations of individuals or broader units such as companies, states, parties, groups or classes, which are interdependent and function dynamically, in which no element can determine the overall functioning of this figuration. Therefore, they are at the limit, undetermined (Elias, 1980). Secondly, he calls attention to the existence of different mechanisms of regulation of this interdependence, ranging from gossip at the micro-level, to the state and market competition at the macro level, passing through several, as even the functioning process of a small configuration of individuals, such as a family, assumes the production, ownership and circulation of a set of information that is mobilized in the management of the bonds among these individuals. other intermediary mechanisms (Elias, 1994; Elias \& Scotson, 2000).

The third idea I use as a starting point is network-actor theory as presented by John Law. To summarize his argument, we can say that social worlds are produced by heterogeneous networks in which not only human elements such as individuals are articulated, but also non-human elements such as objects and technologies (Law, 1992).

The articulation of these three ideas inspires the following question: In what way do digital communication technologies co-participate in the regulation of the interdependence between the elements that compose contemporary figurations? This question addresses phenomena that are both at the center of politics and go beyond it.

For instance, even the functioning process of a small configuration of individuals, such as a family, assumes the production, ownership and circulation of a set of information that is mobilized in the management of the bonds among these individuals. Remembering to congratulate people on birthdays, wedding anniversaries, graduations, and other occasions, are examples of this task of managing interdependence among family members. I choose this example because it is present in the everyday life of many of us and because it allows me to emphasize another element of this experience, which is the role of the Facebook algorithm in providing personal information about birthdays and that demands a certain behavior regarding this information. 
This example allows me to deepen the formulation of actor-network theory, according to which social worlds are the fruit of the co-production of humans and non-humans, to address a specific type of nonhuman, the algorithm. Found in various forms, algorithms allow digital platforms that form the Social $W_{e b}^{2}$ (Facebook, Instagram, Twitter, and YouTube, to name a few) to act on the actions of humans.

Let's talk a little about this tool. In its simplest definition, an algorithm is a standardized sequence of actions used to obtain a result. But the algorithms used by digital platforms to induce users to take action online have at least two major differences with this simple definition. The first is that these algorithms, which we can call complex, are based on artificial intelligence, that is, they are constructed in such a way as to approximate as much as possible models of rational human action involving decision making, problem-solving, and the learning necessary to deal with new situations. This means that this type of algorithm is built to mimic human behavior and thinking (Christian and Griffiths, 2016; Russel, 2013).

There is a second important complexity in these algorithms. It is the fact that they operate on a database that includes not only the information entered by the programmer but also the information generated continuously by the use of the platform by humans. In this sense, every human - or supposedly human - action carried out on a digital platform, whether on computers or smartphones, can become a digital data source and serve as a base of activity for an algorithm. Platforms with a large user base and strong engagement with it, such as Facebook and YouTube, for example, produce gigantic databases. And it is in the treatment of this data that an algorithm can learn to get to know and classify agents and their actions and to deal with new situations, including the possibility of identifying and predicting, in an approximate manner, the behaviors and states of mind of users, as well as their material conditions: whether the are ill, their age, changes in marital status (married, single, etc.).

Now, we can go a step further, because if actor-network theory (Law, 1992; Latour, 2000) teaches us that objects are co-participants in the production of social worlds forming heterogeneous networks, this heterogeneity is not limited to the distinction between humans and non-humans, but also resides in differences among humans themselves, in the form of different agents, and the distinction between non-humans, in the form of different types of object. Thus, the objects that co-participate in these networks are also heterogeneous, and digital algorithms are a specific form of object, a historical novelty that requires examination. Based on these considerations, I would say that the specificity of Social Web algorithms lies in the way in which, through the articulation of artificial intelligence and a database, these objects are capable of acting intentionally on the actions of humans and the actions of other machines.

This specificity of the algorithm technology allows us to reformulate my original question in the following terms: How do algorithms mobilized on the Social Web co-participate in the regulation of interdependence between elements that compose contemporary figurations?

\section{Algorithmic power and programmed sociality}

Contemporary literature dealing with the social effects of algorithms is growing rapidly and a complete presentation of it is beyond the scope of this article. In an anthology published in 2016, and symptomatically titled Algorithmic Cultures: essays on meaning, performance and new technologies, the organizers affirm that algorithms are at the center "of all social processes, interactions, and experiences that increasingly hinge on computation

\footnotetext{
2 The term Social Web designates the creation and organization of sites and software that are organized to encourage and further social interaction. According to Santos \& Cypriano: "web 2.0, sometimes called the second generation of the internet, is fundamentally characterized by its user participation, its openness to use and the network effects it produces. Such participation occurs through a system that stimulates interactions, sharing and exchanges between netizens, that is to say, a system that incites the collaboration of whoever might be available to interact with others through the platform's mediation... involving the notions of exchange, sharing, and collaboration.” (Santos \& Cypriano, 2014:64). And we can say the sociality phenomena built upon these network structures have become a central object for digital sociology (Boyd, 2014).
} 
to unfold; they now populate our everyday life, from the sorting of information in search engines and news feeds to the prediction of personal preferences and desires for online retailers, to the encryption of personal information in credit cards, and the calculation of the shortest paths in our navigational devices" (Roberge \& Seyfert, 2016:1). Among the objects of sociological analysis that have been reconfigured by the presence of algorithms are mechanisms of power. This reconfiguration is the object of this article and is present in a recent, very important body of literature. Thus, based on an examination of how marketing and web analysis companies have implemented sophisticated algorithms to observe, analyze and identify users, forming large online surveillance networks, authors such as Cheney-Lippold have argued that these computer algorithms have the ability to infer users' identity categories based on their web navigation habits, giving algorithms a place in a long history of biopower mechanisms and biopolitical tools (Cheney-Lippold, 2011). Furthermore, other authors posit that contemporary democracy faces an "algorithmic turn", meaning that the data processing and automated reasoning that constitutes the algorithms play a vital strategic role in the conduction of electoral processes, consumer decisions, governing mechanisms and decision-making (Gurumurthy \& Bharthur, 2018). In this article, I intend to contribute to the development of this field by intersecting two lines of research emerging from these texts. The first line inscribes the examination of algorithms in the long history of technologies of power, the second analyzes how the use of technologies of power and political disputes are reconfigured by the "algorithmic turn".

The first step in answering the question with which we ended the previous section is to understand that the mechanisms for regulating interdependence operate as instances of power. To do this, we will take as the starting point the definition of power used by Foucault, according to which power has repressive and productive aspects (Foucault, 1995). In his studies on medical power, psychiatric power, and specific situations, such as pastoral power, Foucault criticizes what he calls the theory of zero-sum power, which affirms that power is the enhancement of the capacities of action of those who are subjects of power relations, at the cost of reducing the capacities of those who are the object of those relations. To the contrary, for Foucault, power relations constitute individuals on both sides. And they do so by increasing the capacity for subjects to act in a given direction, while simultaneously offering them a closed horizon of possibilities for action.

Foucault's definition of the concept of power is a promising tool for analyzing the functioning of the Internet, since the digital platforms that constitute it are constructed as a kind of "open work". That is, their design considers not only the actions of users, but a platform only exists completely when "filled-in" by such actions. In addition, the platforms provide mechanisms that strengthen users' ability to act in the form of communication, production, and dissemination of textual and audiovisual content, information retrieval, memory enhancement, and pre-organization of countless actions. This increase in the capacity for action of users occurs simultaneously to an increase in algorithmic control over user actions, in an effort to maximize user engagement with a platform.

The term Social Web (or Web 2.o), popularized in the mid-200os, emphasizes the multidirectional capabilities of the technologies gathered on the Internet, defining it as an environment of interaction and participation. This means that, instead of simply consuming content made available by the websites, users can and are encouraged to interact with one another through words, images and sounds, the so-called posts. As the capacity for information transmission increased, the possibilities for posting also grew, evolving from texts to drawings and photographs, to music and videos. In this new dynamic, users were redefined as prosumers, that is, as consumers and producers of content. ${ }^{3}$ In this direction, websites, redefined as platforms, were increasingly

\footnotetext{
3 The term prosumer precedes the generalized spread of Web 2.o. It was coined by Alvin Tofler in the 1980s in an attempt to predict future changes in modes of consumption, and, as shown by Costa, the ideas involved had already been developed by Marshall McLuhan and Barrington Nevitt in a 1972 work (Costa et al. 2013). Nevertheless, Web 2.o, with its bidirectional technologies for communication and content creation in virtual medias, provided the ideal environment for the spread of the concept, which went on to be widely employed in marketing studies.
} 
conceived as a co-production between programmers and users. With this in mind, a Facebook page with no personal information and no added friends is a simple digital form that has yet to be filled in, because it is the activity of users and their relationships that fill-in a website.

Another famous example of this dynamic is the YouTube platform, which is constructed not only as a video repository but as a means to create an audience to compete with traditional media, especially broadcast TV. Thus, the platform offers users tools for editing, publishing and popularizing videos. The collaboration between the platform - in the form of tools and algorithms - and content-producing users, simultaneously produces the audience of the individuals themselves, the quantity of users and the number of hours they spend watching their channels and the YouTube platform. This dual production of audience results in possibilities for remuneration through advertising for the channels and the platform. It is thus clear that it involves increasing certain capabilities of action of individuals, while algorithms and the rewards for visualization increasingly induce them to seek an audience on the platform.

Tania Bucher proposes the concept of algorithmic power, establishing an approximation between the Foucaultian definition of power and the mode of operation of the algorithms which is very close to the analytical effort we are making here (Bucher, 2018). She draws attention precisely to the fact that the algorithms of digital platforms, especially those of the so-called Social Web, act intentionally to induce actions in the users and to co-participate in the production of sociabilities. Another important concept presented by Bucher is called programmed sociality. She uses this concept to describe the fact that these algorithms are built to produce social effects. This involves inducing different types of associations between users, such as encounters, memories, praise, criticism, congratulations, etc. With the term programmed, the author not only describes the fact that the algorithm is a computer program but also points to the fact that its work is to gather, and to organize this association, that is, to program interactions among people. Another crucial aspect of programmed sociality is the fact that, through these encounters organized by the algorithm, human agents incorporate norms and values about the social world.

Let's observe both aspects in a concrete situation. If we take the case of Facebook as an example, we will see that the platform constantly notifies users about the activities and status updates of other people that are part of their interpersonal network. It informs if people are near, what they are doing, and what has happened to them, giving users the ability to communicate with these people on the network, to congratulate them, criticize them, and interact with them. In addition, at certain times, for instance, on the birthday of a network member, the algorithm not only informs the date of the birthday but suggests that users congratulate their friends. So algorithms not only publish information, but also prescribe behaviors.

The platform is not limited to providing all the information about all members of an interpersonal network. To the contrary, an algorithm operates by trying to understand what attracts a user's attention and what information, about whom and about what subject and/or event would make a user more likely to respond. Based on the patterns learned, which are always dynamic, an algorithm selects the information that will be sent to the user. The algorithms are not simply a machine production, not even in the cases of machine learning. They are programmed by humans who have been socialized with social norms and values and, therefore incorporate them into the production of social algorithms. But this incorporation goes far beyond the replication of perceptual schemes in which the programmers have been socialized. Even in the cases of machine learning, a fundamental part of the raw material of learning - which consists in the apprehension of patterns - comes from databases that materialize social arrangements and productions ordered over time, and then loaded with historically constructed values and norms.

Another important, but often neglected aspect of the analysis is that these algorithms were fed with the result of anthropological, sociological, and psychological studies gathered by this consumer science of marketing to answer questions such as: what mobilizes people? What makes people connect and how do these 
connections impact their actions? What should be placed in the foreground to attract people's attention and generate engagement? Such studies allow us to understand, for instance, the importance of family, the importance of certain dates and personal statuses, the importance of interpersonal trust in information, among other factors. The studies also show that people mobilize around childhood, situations of animals and children, situations in which the community they believe they are part of is in danger, and others. Once these principles of mobilization and association have been defined, they are introduced in the algorithmic programming and allow the operation of what has been called algorithmic curating, a concept that I will develop further on, which is related to the modes of selection and distribution of the information presented to the user.

But this algorithmic activity is not only about producing social bonds - through which social values are built. It is also a matter of mobilizing existing social ties to produce connection and engagement in the platform. The operation of an algorithm supposes that a user is connected through the computer and, more importantly, the smartphone, since it is mobile and accompanies users throughout the day. For this reason, the primary objective of the platform is for users to install the application on their mobile phones and remain connected at all times. To induce them to perform these two actions, the platform relies on a user's interpersonal networks. Therefore, users are asked to provide access to their list of contacts to allow capturing a social network that already exists within the digital network. It is friends and co-workers who often suggest using an instant messaging tool such as Facebook Messenger or WhatsApp to directly communicate within the interpersonal network. Therefore, the refusal to take part in a digital network can impede the performance of actions within the interpersonal network. Again, following Foucault's concept of productive power, we encounter an increase in a capacity for action combined with a limiting of the field of possibilities for action.

These observations of algorithmic power and programmed sociality lead us to the conclusion that to be socially effective, algorithms cannot be neutral because they need to select the information that is socially meaningful and, by doing so, they update social values. Simultaneously, algorithms perform functions of socialization and operate in power relations to the degree that they strengthen capacities of action on a horizon of action supported by the machinic effort to produce connection and engagement. This definition offers the first answer to my central question about how algorithms co-participate in the regulation of interdependence in contemporary societies. I will now examine some specific situations of this regulation.

\section{Algorithms and the social production of time, space, and identity categories}

The idea I would like to develop in this section is that the sociality built through digital communication technologies produces and is produced by content that fill-in the categories of time, space, and identity and that this fact has political consequences. Readers familiar with sociological theory will recognize a Durkheimian theme here, addressed in the classic The Elementary Forms of Religious Life (Durkheim, 1989). As Horst and Miller (2015) show, it is necessary to recognize the multiple planes of the internet's materiality, and among them, what the authors call contextual materiality is exactly how subjects' experiences on digital platforms take place within a material frame of time, space, and identity that is co-produced by the organization of the platforms and the agency of users. We can, therefore, argue that digital platforms give materiality and specific meanings to these categories and therefore serve as a framework for political associations and struggles.

The relationship among the definitions of time, space, and identity, on the one hand, and political mobilization on the other, lies at the heart of Benedict Anderson's concept of an Imagined Community. Indeed, the idea that communication technologies in general build meaning and materiality for these categories

\footnotetext{
4 The concept of algorithmic curating has been developed in the field of communication studies with a similar meaning to the one I utilize in this text. According to Correa \& Bertocchi, there is an overabundance of data on the digital web, and algorithms have performed a variety of actions involving organizing these data through criteria and selections (Correa \& Bertocchi, 2012).
} 
are at the basis of Benedict Anderson's conceptual discussion of the role of maps, censuses, monuments, literature, and, above all, the press in the production of imagined nations as communities (Anderson, 1983). The possibility to materialize when, where, and who (including the definitions of us and them) as a collective experience depends on collective means of representation and communication. In the gradual production of imagined communities, newspapers play a fundamental role thanks to their periodicity, the chronological and spatial organization of their narrative, their themes linked to territories and populations, and their emphasis on the very existence of the national. Thus, social media materializes categories of time, space, and identity and serves as a framework for the constitution of what Weber conceptualized as community social relations, that is, based on a shared co-belonging among the agents (Weber, 2004: 81).

Digital platforms are, first and foremost, communication technologies. But they are not merely a private face-to-face communication between a sender and a receiver. Platforms are not just an arena where individuals can relate. First of all, platforms harbor and enable collective communication. Several individuals produce and receive information simultaneously. Secondly, the distribution of information (what will be seen, under what conditions, and by whom) is organized by the digital platform. This makes platforms social communication tools. And it is in this condition that they generalize categories of understanding.

A well-known expression of social communication exercised by platforms and the way they generalize categories of understanding is the timeline, a tool that organizes what circulates as information and among whom. This organization is made by algorithms that operate from three domains: a) patterns of action and classification inscribed by programmers in the source code; b) patterns identified by machines in the actions and relations of human actors; and c) patterns identified by humans in the actions of machines and other humans. A timeline is the fruit of this circular relation in which machines and humans act and modify their actions based on the always dynamic understanding of how the other operates. In this sense, a timeline is co-produced by humans and machines. But this co-production does not establish an asymmetrical relation between the parties, since the organization of the social communication that permeates and constructs the platform rests, ultimately, on the algorithms. A timeline is the individualized face of a collective organization and not an individual organization per se.

The first aspect that I want to emphasize is the fact that a timeline produces a temporal ordering of the contents presented to the user. But, in addition to arranging the contents chronologically, a timeline forms an arrangement of the perception of time. Like a clock or a newspaper, it marks time for readers, informing them of what just happened - what is urgent; what happened some time ago - in the form of memories; what is the subject of the day, and other markings of time. Moreover, a timeline builds its own rhythm for updating information - the so-called real-time - which is briefer than that of other media, such as newspapers and TV news, and thus induces users to consult it constantly.

Another dimension that crosses a timeline is the dimension of place. Most digital platform applications - Facebook, Twitter, Instagram, among others - have mechanisms of spatial localization that allow users to identify from where other users access their accounts and post their contents. The main mechanism consists of extracting information from GPS devices on smartphones, but there are other features, such as the triangulation of cellular antennas, IP (internet access points) tracking, and the identification of patterns of displacement and location created by tracks left in online navigation. Thus, one of the central elements used in organizing a timeline is the definition of place, since the algorithm considers the location of users in the selection of the subjects and posts that are published.

The third element in the organization of timelines is the interpersonal network in which users are involved. This network is formed by a structured set of people and/or entities that produce content from which the algorithm extracts a selection and publishes it on users' timelines. Since we discussed this theme above, I only 
want to emphasize the idea that this flow of information within the interpersonal network narrows the bonds between these agents and builds a collective experience of co-belonging as it produces a social reality of people interconnected by common events.

To summarize, since digital platforms function as social media spaces, the algorithmic ordering of information produces effects of simultaneity, by transmitting information at an algorithmically ordered pace and by broadcasting the same information at the same time in a network. This order also produces contiguity effects because algorithms consider spatial location in the distribution of information. In addition, the very definition of place and common space is determined by the way information is distributed. Finally, this interpersonal network in which algorithms produce a common definition of time and space is also the target of the production of an idea of us and them. That is, the algorithm promotes the existence of groups by distributing information about events and actions that are supposedly of common interest and that demand a collective positioning.

\section{The business model of digital corporations: marketing as philosophy, algorithmic activity, and collaborative human actions as method}

Since the early 200os, the technological innovations found on the Internet have been hailed for their potential to democratize politics by transforming relations between citizens and institutions, whether they represent the state or private corporations (Castells, 2003). The representation of the cyber-activist, imagined as a fighter who, thanks to their expertise in programming, unlocks state and corporate secrets, was exemplarily embodied by Wikileaks in the famous leak of official US documents in 2010.

Paradoxically, almost parallel to this utopian project that is still under development, the Internet has seen a growing monopolization by some digital corporations, especially Google, Amazon, and Facebook. If the Internet is a network of networks, these corporations form gigantic sub-networks that aspire - especially Facebook - to capturing all the connections and navigation data that an individual generates on the network. Thus, they aim to contain the entire experience that each user has on the Internet.

When we discuss how algorithms play a role in regulating interdependence, we are addressing not what communication technologies can be, but rather how they are used by these large digital corporations. This is because the broad collective experience of using the Internet involves the experiences of the users of these corporations, at least in the past ten years. ${ }^{5}$

We discussed above the place of marketing in the organization of digital platforms and their fundamental intention to obtain increasing connection and engagement of users. We return to this topic to examine in more detail how it organizes the operation of the algorithms.

In general, the algorithmic activity of the platforms and the work of users are naturalized by a discourse that assumes the existence of a neutral rationality of machines and that users understood as communities supposedly share altruistic values (Christian and Griffiths, 2016; Russel, 2013). However, one aspect that is sometimes neglected in the discussion of artificial intelligence and which is particularly important to how sociology understands human intelligence and action is intentionality, that is, the motives for action and reflexive monitoring of action (Giddens, 2000). To some extent, this discussion is obscured by the idea that technology is neutral in terms of its intention and by the belief that motives for action can be summarized in the generic idea of "pleasing the user". However, the closer Social Web algorithms come to artificial intelligence the more they are permeated by intentionality and their focus is not the desire of users, but the interests of digital corporations, which generally consist of finding ways to monetize users' Internet activities. 
As Dominic Cardon has shown, when the Internet began its broad expansion in the 199os, Webmasters, in their search for information that could be monetized, developed ways to measure the number of visitors to their websites. They were inspired by a basic operating procedure of traditional media such as TV and radio, which consisted of measuring audiences to use the data gathered when offering their media as a vehicle for advertising (Cardon, 2015). In this regard, the views were conceived as an audience. This mechanism later became the basis for a broad set of algorithms designed to measure views of a web page, which allowed digital platforms to compete with traditional media for corporate advertising. Currently, Google Analytics, which is a free service offered by the company to certify the number of views on a website, is the dominant tool used by websites that exist outside the spaces of the other large Internet companies, and audience measurement continues to play a role in monetization efforts. But monetization was guided by another fundamental marketing principle: the effort to know the characteristics of users and their online modes of action, for which simply counting visits to a website was not enough.

This need was met, as Cardon showed, in 1994 when a Netscape browser engineer invented the cookie, or connection statement, which is a technical procedure that stores the data exchanged between a browser and a page server in a text file created on a user's computer (Cardon, 2015). Cookies establish a link between the browsing program used on a particular computer, its IP, and an HTML page, and their function is to memorize information about users' online activities, such as passwords, items added in the shopping cart in an online store, hyperlinks that were clicked before, and others. This is the basic tool used by search engines to identify navigation patterns.

The initial goal of cookies was to increase the efficiency of navigation and the file associated to the cookie automates a series of actions and saves the user's time. More importantly, however, this file "has become the Trojan horse of advertisers and digital corporations by penetrating the privacy of Internet users" (Cardon, 2015:13). Cookies provide detailed information about users' browsing histories and their online actions - what they click on, how long they are logged on, and which websites they visited. This allows corporations to identify what attracts the attention and engagement of users, by providing material to build user profiles. In this regard, the more users on a platform and the greater their engagement, both in the older sense of simply accessing and clicking, and in the prosumer sense of their participation in the production of content on platforms, the greater the amount of information captured by corporations and the larger their databases, which become valuable assets. Since the effectiveness of an algorithm is directly related to the size and quality of the information it contains, a virtuous circle is established between programming, algorithmic learning, and the database.

This leads us to the second point that I want to emphasize, namely that the logic of economic functioning of these digital corporations is based on the idea of replacing human work paid for by the company as much as possible, on one hand by the activity of algorithms whose effectiveness, as we have seen, depends on the size and quality of the database; and, on the other hand, by the collective and free work of users, which in turn depends on users' commitment and willingness to evaluate agents, services, and content posted, in what has been conceptualized as a "collaborative culture".

One of the results of this logic, as we can see in companies such as YouTube, Airbnb, Facebook and others, is the small number of officially employed workers, compared to the large number of users. In this sense, the collaborative ideal from the early days of the Internet culture, as identified by Castells (2003), is captured here entirely by a logic of economic accumulation. The prosumers are not only consumers and content producers, they are also evaluators of services, producers of information about posts, about other users, about services, and about workers engaged in the platform. Thus, the consumer, producer, and unpaid worker are compiled into a single character as the engaged user. 
Moreover, the effort to articulate algorithmic activity and collaborative human actions is part of the method of economic management of digital corporations. This articulation allows an exercise in curating that can evaluate services, people, and mainly contents that circulate on the network, dispensing the need for paid human work. Thus, the selection and diffusion of information is accomplished through the articulation between an algorithmic curation and a collective curation of the users that is also algorithmically mediated.

To conclude, we can say that all the corporations that organize the Social Web have two fundamental products: the attention and actions of users that can be monetized through ads related to the audience of the platform; and the information extracted from these actions and the attention of the users, which can be monetized by identifying their characteristics and behavioral patterns. ${ }^{6}$ In this regard, Social Web algorithms, that is the artificial intelligence articulated to a database, are driven by the goal of maximizing the production of information about users and their engagement on a platform, such as the time they spend online, their production of content and participation in collaborative actions to evaluate both posts and other users. This configuration gives meaning to the famous phrase: "When the service is free, it means you are the product." To which we could add: you are the product and the unpaid worker.

\section{The social organization of knowledge in the era of the algorithm}

To return to the examination of how algorithms mobilized on the Social Web co-participate in the regulation of interdependence, I want to return to the expression "algorithmic curating" that I used above and explain its meaning. The root meaning of curate is to care for and store something. But it is not about storing everything, but rather selecting what deserves to be kept as part of the care. In the field of art, the term incorporates the idea of caring and selecting to exhibit in an organized way and make clear what deserves to be preserved and or promoted. So how do algorithms operate as curators?

Let's see. Socio-digital networks interlink humans and objects and since the studies of the so-called "Chicago School", we know that interaction among individuals supposes what Thomas conceptualized as "definition of the situation", such as the fact that any individual action directed at another depends on a perception about the nature of the other and about the nature of the situation in which the interacting individuals are involved (Thomas, 2005). This concept and its broader implications are properly developed in an analysis that Gilberto Velho dedicated to Goffman's work. According to Goffman: "Every interaction, from the Simmelian dyad to the more complex social networks, depends on basic understandings that permit elementary sociability to the sharing of broader collective projects" (Velho, 2008:147). Velho quotes Goffman: "Information about the individual helps define the situation, making others capable of knowing in advance what he will expect from them and what they can expect from him. Thus informed, they will know the best way to act to obtain a desirable response". (Goffman apud Velho, 2008:147).

Velho draws attention to the fact that the definition of the situation should not be thought of as a consensus between the individuals that are interacting, nor does it assume transparency and absolute visibility of the agents interacting. To the contrary, the definition of a situation is structured through a dynamic of mutual performances and decoding that implies concealment and often produces misunderstandings.

\footnotetext{
6 The Cambridge Analytica scandal is one of the strongest examples of the ability of algorithms to observe, analyze and identify user categories and their use in political action. In March 2018, The Guardian, The New York Times and The Observer newspapers published a series of articles about a company that collected data from more than 50 million users without their consent, via Facebook and online psychological tests that were falsely presented as personality quizzes. This massive amount of data was used to produce behavioral and psychographic profiles for user categories, supporting the creation of targeted propaganda, polarizing messages and fake news directed to each category according to this classification. The ultimate goal was to both predict and induce behaviors in specific elections and plebiscites, and Cambridge Analytica apparently played an important role in the Brexit referendum and the 2016 US presidential campaign (Gurumurthy \& Bharthur, 2018:41)
} 
As we can see, interaction between individuals assumes social knowledge about several subjects: the individuals and their motivations, the nature of that interaction, the fundamental themes and problems at play, the place and moment of interaction, and others. The meaning of the term social here refers to the fact that individuals do not freely and individually produce such knowledge. It involves a collective production that depends on the mechanisms of social communication. Thus, we will see in the last section of this article that, in addition to the misunderstandings pointed out by Velho, we affirm that there is a political dimension involved in the concept of definition of the situation derived from disputes around its production.

In an earlier text (Ramos, 2015), we affirmed that when Simmel proposed a sociology of secrecy and stated that "all relations among people rest on the precondition that they know something about each other," he was emphasizing a basic aspect of social relations, which is the necessary presence of the dialectical pairs trust/ distrust, reveal/hide and lie/tell the truth (Simmel, 1999), involved in the self's perception of the other and also in the self's presentation to the other. Therefore, we can affirm that "there is no social relation that is not mediated by the perception that agents have of each other, and in the construction of this perception, what is hidden and what is shown, what is known, and what is suspected have a key role. They are, as Maldonado (2011) shows, in the final instance, social forms of distribution and administration of information and knowledge. Since this is a characteristic of all social relations, we can only ask how it is present in the social relations mediated by the use of computers, smartphones and tablets on the Internet" (Ramos, 2015).

Any experienced user of a Social Web platform - Facebook, Instagram, Twitter, among others - realizes, somewhat consciously, that they perform a persona online in relation to other individuals. What may not be as clear to the users is the role of algorithms in selecting a portion of the information that an individual posts and diffusing these posts selectively. This is the first meaning of the term algorithmic curating, which is the role of algorithms in caring, storing, and collectively disclosing information considered to be important about individuals.

This effects how individuals perform an online identity. If even a face-to-face interaction of individuals assumes a dialectic of showing and hiding, to this is added, in the case of online interaction, the mediation conducted by algorithms that selects what will be shown to whom, how often, and in what way. This takes us farther from an individual's control over what is shown and hidden, since when they act online, they produce information about themselves and about those with whom they are associated. This is why the issue of privacy as an individual right is a misplaced because individuals never produce information only about themselves. The algorithm takes the network itself as an object and subject, and each individual profile is treated as an access point to the network. Another important aspect is the fact that individuals do not perform in front of a single other, but many others, on a network. Digital personas and their networked existence are therefore co-produced by individuals and algorithms.

The counterpart of this co-production of digital personas is the co-production of the definitions of the situation. We stated above that Social Web platforms operate as tools of social communication since they transmit information in a collective and organized manner. As such, as a result of the user's actions and algorithmic activities, platforms present individuals with an organized set of information about who the others are, what is worthy of attention, and how the individuals are perceived. We argued above that algorithms co-participate in the social production of the categories of substance and of the contents of identity, as well as the categories of time and space. In this sense, the algorithms are consequently co-producers of the social definitions of a situation, and here we have the second meaning of the term digital curatorship, as mechanisms of social communication and co-producers of categories of understanding.

Let's deepen the idea of co-participation. Every social network is a dynamic phenomenon and as a form of power, algorithms must account for this dynamism. This means acting in a contingent and relational manner. Agents come and go from the network, as well as change themselves in terms of presence and mode 
of participation. To understand a network is to understand this dynamic of participation and belonging. The algorithms consider this dynamic by dealing with both moments of greater and lesser adhesion. In both cases, the goal is to produce adhesion where it does not exist or is decreasing and to increase adhesion where it exists. Apart from the goal of increasing adherence and action, an algorithm has no other purpose and its activities are contingent and relational. It depends on the nodes, on the intensity of the connections, and on whatever may circulate on the network. In this regard, algorithms contribute to the definition of the situation by organizing social communication, but without intentionally defining the content of the definition of the situation. The intentionality of the algorithms, as we have said before, is to produce connection and engagement.

The meaningful content of the definition of situation is constructed by the actions of humans and by the activity of the algorithm on these actions. The latter acts on the most promising nodes and on everything that can intensify adhesion. One of the main lessons of marketing as a science of consumption is the importance of mobilizing feelings to stimulate consumption. Therefore, the activity of the algorithms in the organization of the information is guided with an intent to mobilize feelings. This algorithmic activity is part of the production of both the echo chambers on Facebook and the intensification of indignation on Twitter, and the spread of controversy on YouTube. In each case, it is about working on what creates bonds and actions through the organized dissemination of messages.

Let's analyze the case of YouTube and YouTubers. These are people who make money by delivering firstperson videos on YouTube, so the term relates to a new professional modality. Monetary compensation can be achieved in many ways, but the most common is the payment made by the platform itself, according to the number of viewers who watch a video and the time they spend watching it. ${ }^{7}$

In their videos, most YouTubers explicitly construct a performance of authenticity, marked by a collapse of the distinction between what is public and what is private, by the display of self, of their opinions and impressions about something, and aspects of their privacy, such as their home, clothing, and personal relationships. This performance does not only operate when YouTubers talk about themselves. Even product reviews or tutorials of techniques are performed as an authentic experience since they are performed in the first person. As Fonseca shows us, in this performance of authenticity, YouTubers often present themselves as people within reach of users, as opposed to TV and movie stars, for example. They also use a very intimate and emotional language to create a sense of identity between the audience and the person who produces the videos. YouTubers aim to build an emotional relationship with users who watch the videos on their channels so that these people evolve from interest to admiration and from there to a sense of proximity and personal identification with them (Fonseca, 2019).

But the performance of authenticity YouTubers employ is not the only engaging production tool. A key role is played by the algorithm that recommends videos for users to watch. According to Fonseca, Google defines YouTube as a "destination platform." This means that the platform strives to capture the user's attention in an increasingly intense and continuous manner, with each video seen as a thread in a web that will entangle users. This is initially done through notifications sent to users' mobile devices or computers informing them about news from the channels to which they have subscribed. Once users access the platform to watch new videos, they are offered a set of recommendations that are assembled by the algorithm based on

\footnotetext{
7 According to Luz, the term youtuber was incorporated into the Oxford English dictionary in 2016, and "refers to individuals who add, produce, or appear in videos on the YouTube platform. Although only recently recognized with a dictionary entry, the expression has been used for a long time by both the YouTube platform - especially by content creators when they want to refer to their performance - and in other media. In Brazil, the term first appeared in print media when news stories appeared about the opportunity to make money by creating videos for YouTube. On the website of the newspaper O Globo, for instance, articles related to the topic have been published since 2015, and in the Folha de São Paulo since June 2013. It is possible that the Brazilian press followed international trends, since the The New York Times had used the term in 2006, and The Washington Post in October of the same year." (Luz, 2018: 11)
} 
what it identifies as user consumption patterns. According to the platform's official discourse (YouTube help), the channel recommendations are based on the following factors: which channels are watched by the same users; if the videos address similar topics; if the channels are appropriate for the same audience.

However, reverse-technology experiments, such as those done by programmers like Chaslot (2017), show that YouTube's Artificial Intelligence recommendations were designed to maximize the time that users spend online and that by doing so, increase the promotion of inflammatory videos, and thus perform a disproportionate role in the dissemination of so-called alternative facts. As Chaslot depicts in his blog: "We all heard about conspiracy theories, alternative facts and fake news circulating on the internet. How do they become so popular? What's the impact of the state-of-the-art algorithms on their success? Having worked on YouTube's recommendation algorithm, I started investigating, and came to the conclusion that the powerful algorithm I helped build plays an active role in the propagation of false information". (Chaslot, 2017).

Indeed, Chaslot shows in his experiment that it is not true that YouTube simply recommends what people like, since "liking" and "disliking" a video has little impact on what is recommended. He gives as an example the videos that claim that Michelle Obama "was born as a man". These videos have more dislikes than likes but are still highly recommended by YouTube, which leads to the conclusion that YouTube seems to place more weight on the number of views of a video and the time spent on them than on how they are evaluated by users. For this reason, if videos with absurd theories, such as "the earth is flat," for example, keep users online for more time than videos claiming "the Earth is round," videos with contents related to the flat-Earth theory will be favored by the recommendation algorithm and this produces a snowball effect that drives conspiracy theories since, let's not forget, viewing the videos generates compensation from the platform to owners of the channel.

As the author explains in his blog: Once a conspiracy video is favored by the A.I., it gives an incentive to content creators to upload additional videos corroborating the conspiracy. In turn, those additional videos increase the retention statistics of the conspiracy. Next, the conspiracy gets recommended further. Eventually, the large amount of videos favoring a conspiracy makes it appear more credible. For instance, in one of the "flat earth" videos, the author commented: - There are 2 million flat earth videos on YouTube, it cannot be B.S.! (Chaslot, 2017).

The example of conspiracy theories is extreme, but the importance of this quote is to show that the way that algorithmic mechanisms regulate the promotion of videos and stimulate their production leads to the organized dissemination of certain contents, which contribute to the predominance of a specific definition of the situation, both in its definition of what is real and what is not - as in its affective aspects - what is valuable and what is repugnant.

\section{Conclusion: algorithms, social currents, and the political aspect of the definition of situation}

...there are other facts that, without presenting these crystallized forms [of institutions], have the same objectivity and the same ascendancy over the individual. It is what has been called social currents. Thus, in a large assembly, the great movements of lively enthusiasm, indignation, and piety that take place have no particular origin. They come to each of us from the outside and can drag us along without us wanting them to do so. (Durkheim, 1984:4).

With this description of a conspiratorial snowball that we see above, we approach the phenomenon conceived by Durkheim as social currents. In fact, there seems to be little to add to this centennial quote from Durkheim if we tried to describe the waves that drive interactions between individuals on Social Web platforms. Here the concept of social currents is understood as a certain articulation of facts, ideas, and feelings that coerces individuals and operates through movements of opinions, among crowds, or restricted groups, influencing the perceptions and actions of individuals. The concept can, at least partially, describe how these interpersonal networks either become more narrow or expand with the circulation of certain facts, issues, 
and problems, as well as the increase of affective and emotional voltage in the passage of these currents. It allows us to understand the moral demands for taking positions aimed at individuals. It gives us clues about what some authors have studied, such as the lynching of reputations, as well as what they describe as moments of moral panic.

But there is something to add. Firstly, the algorithms operate in this place of an absence of origin as identified by Durkheim. They possess the humility of things conceptualized by Miller, in which the more effective the objects are in their ability to affect the perceptions and actions of individuals, the more invisible that capacity becomes (Miller, 2013).

Secondly, there are individuals who, either alone or organized in groups or institutions, specialize in understanding the patterns of action of algorithms and the action on their activities, thereby obtaining results that benefit them. I classify them as digital entrepreneurs. With this expression, I want to emphasize the fact that they appropriate not only the tools offered by the platforms to increase their action, which is expected of the users as a whole, but they also understand how to act on the activity of the algorithms to make them work for their own projects, causing the digital machine to operate in favor of their interests. The most famous case involves the Google algorithm that, since the 199os, classifies website relevance according to what the users are searching for and that began to have important effects in the production of online pages. Soon, website administrators began to develop practices that have been termed Black Hat SEO, which consist of tricks to inflate the importance that Google's algorithm gives to their websites and position them at the top of the search results. At the limit, this ability to drive algorithmic activity is considered by programmers and platform administrators as cheating. In this case, it is a matter of obtaining economic results by manipulating algorithms. But this same principle was soon applied to other algorithms, and in particular to the Social Web which, as we have seen, is involved in the production of programmed sociality.

A tragic example of this expertise in utilizing algorithmic activity to build a political consensus can be found in the use of Facebook in the spread of hate speech against the Rohingya Muslim minority in Myanmar. In August 2018, the UN formally accused the army of Myanmar of the crime of genocide and investigations revealed that Facebook had been widely used as a tool to legitimate the massacres. According to journalist Paul Mozur of The New York Times, based on their psychological warfare studies, members of the Myanmar armed forces created Facebook pages that appeared to be dedicated to Burmese pop stars, models and other celebrities. They accumulated more than a million followers by posting news and rumors about the celebrities, while simultaneously spreading fake news about the Rohingya minority, presenting Islam as a global threat to Buddhism, reporting false rapes of Buddhist women by Muslim men, and forging pictures of people who had supposedly been murdered by Rohingya. The posts were accompanied by inflammatory comments made by seemingly common users, although in reality, fake profiles had been created to stimulate the posts and generate a semblance of public opinion. One of the reasons this hate speech went unnoticed by Facebook was that it had very few employees who could read Burmese and identify the content of the messages. Curating was almost exclusively a task for the algorithm, which privileged the popularity and the seemingly organic sharing of the messages on these popular pages, leading Facebook to amplify the growth of the hate speech (Lee, 2019; Mozur, 2018).

In this case, the manipulation of the algorithm had extremely dangerous political impacts based on the vulnerabilities of this business model in which the information is curated through a co-participation between the algorithm and the collaborative work of users. Since even "collaboration" among users is mediated by the algorithms, we can see that in the model idealized by the administrators of the digital platforms the algorithms are more important for curating the information. Hence, those humans that can interfere with the activity of the algorithms also become capable of interfering with the collaborative action, and this has political implications. Let's see how. 
According to Bourdieu, one of the crucial aspects of the political expression of the class struggle is the dispute over knowledge of the social world and of the categories that allow naming it, in such a way that it involves a "theoretical and practical struggle for the power to conserve or transform the social world, conserving or transforming the categories of perception of this world". He continues: "The ability to cause to exist in an explicit state, to publish, to make public, that is objectified, visible, speakable... that which, by not having reached an objective and a collective existence, remained in a state of individual or serial experience, unease, anxiety, anticipation, restlessness, represents a considerable social power, that of constituting the groups, constituting the common sense, the explicit consensus, of any group". (Bourdieu, 1989:142 - emphasis by the author).

To the extent that certain human agents develop both expertise in understanding the algorithms' patterns of activity, as well as techniques and practices of their conduct, which involves collaborative action mediated by them, this expertise allows these agents to engage in disputes for the definition of the situation, that is to make explicit and name tensions, fears, and forms of unease that exist at the level of objective experience. Thus, to the degree that their strategies prove to be effective, they are able to use the way the algorithms operate to curate information at the service of disseminating a given definition of the situation and transforming it into a social current, in the Durkheimian sense, and from there, to create groups by creating the common sense of these groups.

As mentioned, the algorithms of Social Web platforms make an effort to produce and organize socialities by curating content, recommendations, and prescriptions directed at users. To return to our initial question, we can conclude that it is by curating information, administering its collective storage and diffusion, and from there, the production of definitions of the situation, that the algorithms mobilized in the Social Web co-participate in the regulation of the interdependence among the elements that compose contemporary figurations. And it is through the strategic action of human agents on the activity of algorithms that this algorithmic curatorship has contributed to the predominance of certain definitions of the situation that in turn are an intrinsic part of the constitution of social currents that have political effects.

Submitted: April 17, 2019

Approved: July 03, 2019

Revised by Jeffrey Hoff

\section{References}

ANDERSON, B. 1983. Imagined communities: reflections on the origin and spread of nationalism. New York: Verso. BOURDIEU, Pierre. 1989. "Espaço social e gênese das classes". In: O poder simbólico. Lisbon: Editora Difel. pp. 133-161.

BOYD, Danah. 2014. It's complicated: the social lives of networked teens. New Haven; London: Yale Universit Press.

BUCHER, Taina. 2018. If... Then: Algorithmic Power and Politics. New York: Oxford University Press.

CASTELLS, Manuel. 2003. A galáxia da Internet: reflexões sobre a Internet, os negócios e a sociedade.

Trad. Maria Luiza X. de A. Borges. Rio de Janeiro: Jorge Zahar.

CARDON, Dominique. 2015. À quoi rêvent les algorithmes. Nos vies à l'heure des big data. Paris:

Seuil/ La République des Idées. 
CHASLOT, Guillaume. 2017. "How YouTube's A.I. boosts alternative facts”. Medium, March 31, 2017. Available at: https://medium.com/@guillaumechaslot/how-youtubes-a-i-boosts-alternative-facts-3cc276f $47 \mathrm{cf} 7$. Accessed on March 17, 2019.

CHENEY-LIPPOLD, John. 2011. "A New Algorithmic Identity: Soft Biopolitics and the Modulation of Control". Theory, Culture \& Society, 28(6): 164-181.

CHRISTIAN, Brian; GRIFFITHS, Tom. 2016. Algoritmos para viver: A ciência exata das decisões humanas. São Paulo: Companhia das Letras.

CORRÊA, Elizabeth Saad; BERTOCCHI, Daniela. 2012. "O algoritmo curador - O papel do comunicador num cenário de curadoria algorítmica de informação”. In: Compós - XXI Encontro Anual da Compós - Associação Nacional dos Programas de Pós-Graduação em Comunicação, 2012, Juiz de Fora. XXI COMPÓS: Juiz de Fora / MG, 2012. Mimeo.

COSTA, A. et al. 2013. "A emergência da concepção do prosumer na era da comunicação digital".

Universidade de São Paulo. Escola de comunicação e artes. Programa de Pós-graduação em ciências da comunicação. São Paulo, 2013. Mimeo

DURKHEIM, Emile. 1989 [1912]. As formas elementares da vida religiosa: o sistema totêmico na Austrália. São Paulo: Paulinas. . 1984 [1895]. As regras do método sociológico. São Paulo: Editora Nacional.

ELIAS, Norbert. 1980. Introdução à Sociologia. Espaço da sociologia. Trans. Maria Luísa Ribeiro Ferreira. Portugal, Lisbon: Edições 70. . 1994. O processo civilizador: formação do Estado e civilização. Rio de Janeiro: Jorge Zahar. .; e SCOTSON, John. 200o. Estabelecidos e outsiders. Rio de Janeiro: Jorge Zahar.

FONSECA, André. 2019. "Youtubers são mais influentes que professores". Medium, Feb. 13. 2019. Available at: https://medium.com/@azevedofonseca/youtubers-s\%C3\%A3o-mais-influentes-que-professores5edfa1oc5126. Accessed on March 17, 2019.

FOUCAULT, Michel. 1995. “O sujeito e o poder”. In: H. Dreyfus; P. Rabinow (eds.), Michel Foucault uma trajetória filosófica. Rio de Janeiro: Forense Universitária. pp. 231-249.

GIDDENS, Anthony. 200o. Dualidade da Estrutura - Agência e Estrutura. Oeiras: Celta Editora (press company). GURUMURTHY, Anita e BHARTHUR, Deepti. 2018. "Democracy and the Algorithmic Turn”. SUR, 15(27): 39-50.

HORST, Heather; MILLER, Daniel. 2015. “O Digital e o Humano: prospecto para uma Antropologia Digital”. Paragraph, 2(3): 91-111, July/December 2015.

LATOUR, Bruno. 200o. Ciência em Ação. Como seguir cientistas e engenheiros sociedade afora. São Paulo: Unesp (Publisher).

LAW, John. 1992. "Notas sobre a teoria do ator-rede: ordenamento, estratégia e heterogeneidade" (Translated by Fernando Manso). Available at: http://www.necso.ufrj.br/Trads/Notas\%20sobre\%20a\%20 teoria\%20Ator-Rede.htm. Accessed on March 17, 2019.

LEE, Ronan. 2019. "Extreme Speech in Myanmar: The Role of State Media in the Rohingya Forced Migration Crisis". International Journal of Communication, 13: 3203-3224

LUZ, Juliana. 2018. “PROFISSÃO YOUTUBER: Carreira, Empreendedorismo e Influência digital”. Master's

Dissertation in Anthropology. UFF/PPGA, Niterói.

MALDONADO, Simone. 2011. Georg Simmel: Sentidos, Segredos. Curitiba: APPRIS.

MILLER, Daniel. 2013. Trecos, Troços e coisas: Estudos antropológicos sobre a cultura material. Rio de Janeiro: Jorge Zahar.

MOZUR, Paul. 2018. “A Genocide Incited on Facebook, With Posts From Myanmar's Military”. The New York Times, NY. Oct. 15, 2018. 
RAMOS, Jair. 2015. "Subjetivação e poder no ciberespaço. Da experimentação à convergência identitária na era das redes sociais". Vivência: Revista de Antropologia, 1: 57-76.

ROBERGE, Jonathan; SEYFERT, Robert. 2016. "What are algorithmic cultures?”. In: Jonathan Roberge \& Robert Seyferth (eds.), Algorithmic Cultures: essays on meaning, performance and new technologies). London: Routledge. pp. 1-25.

RUSSEL, Stuart J. 2013. Inteligência artificial. Rio de Janeiro: Elsevier.

SANTOS, F. C.; CYPRIANO, C. P. 2014. "Redes Sociais, Redes de Sociabilidade”. RBCS, 29(85): 63-78 .

SIMMEL. Georg. 1999 [1908] "O Segredo" (Translated by Simone Carneiro Maldonado). Revista Política \& Trabalho, 15: 221-226.

THOMAS, William I. 2005. "La definición de la situación [1923]". Cuadernos de información y comunicación, 10: $27-32$.

VELHO, Gilberto. 2008. "Goffman, mal-entendidos e riscos interacionais". Revista Brasileira de Ciências Sociais, 23(68): 145-148.

WEBER, Max. 2004 [1922]. “Conceitos sociológicos fundamentais”. Economia e Sociedade, 1: 3-35.

Jair de Souza Ramos

Professor in the Faculty of Sociology and the Graduate Program in Sociology at the

Fluminense Federal University (Niterói, Brasil). Coordinator of the Digital Sociology Laboratory. https://orcid.org/0000-0002-8004-805X

Email: jair.souza.ramos@gmail.com 